\title{
Exceeding Evidence: Photography Theory and Global Climate Model Visualizations
}

\author{
Tim Corballis ${ }^{a}$ \\ Keywords: climate, scientific modeling, photography, aesthetics \\ https://doi.org/10.1525/001c. 28273
}

\begin{abstract}
In "Exceeding Evidence," I develop an interpretation of climate model visualizations based on insights from aesthetic and photography theory. Through this interpretation, I hope to redeem climate model images from their association with a dominating and removed "Earth from space" perspective (as made in T. J. Demos's Against the Anthropocene [2017]). I draw on the observation from photography theory that images can be read either for their comprehensible, narratable information or for the ways in which their detail exceeds comprehension and narrative. This insight suggests that climate model images, like photographs, might be used for more than just evidence-they might give a sense of the world's excess over our ability to understand it, and so a connection with the world "in its own terms." To this end, I give a close reading of two visualizations made by NASA's Scientific Visualization Studio, based on global climate model and satellite data of carbon dioxide levels during 2015. The first visualization not only projects the data on a global map but also expands it into a three-dimensional cylinder. The second demonstrates how satellite data is integrated with model data. These visualizations are interesting for more than the evidentiary and rhetorical uses of climate model visualizations - they also offer a rare if not unique disclosure of the planet as a whole.
\end{abstract}

Climate models have offered a vast store of knowledge about the circulation and interplay of Earth's atmosphere and oceans, as well as warnings and tools to argue for the urgency of political action. They have also offered us a rich store of imagery. Often finely detailed, often showing views of the whole world projected decades into the future, these visualizations feed into the production of knowledge and the case for action. The science and politics of climate change form the images' "big story" - a story of Earth's physical processes, and the ways they are changing and might change further under different emissions scenarios. However, the visualizations can bear another look, one that is sympathetic to the big story but sees_or feels_-something else as well.

In this article, I will offer an interpretation of climate model images, drawing on and in conversation with the ways photography theorists from Roland Barthes to Kaja Silverman have interpreted photographs-as images whose effect is one of connecting to their subjects, even as they frame and mediate them. Applying these arguments from photography theory allows us to ask

\footnotetext{
a Tim Corballis is an interdisciplinary researcher and Senior Lecturer at the Centre for Science in Society at Te Herenga Waka Victoria University of Wellington, Aotearoa New Zealand. He teaches and researches at the intersection of the arts, humanities and sciences. His research interests are wide-ranging, including aesthetic and political theory and the interpretation of the sciences in aesthetic terms. He also has an established creative practice as a novelist, art writer and collaborator in the arts. His books include most recently Our Future is in the Air (Victoria University Press, 2017), a literary time travel and alternative history novel, and R.H.I. (Victoria University Press, 2015), a pair of linked novellas on psychoanalysis, architecture and communism. He works in collaboration with lens-based artist Fiona Amundsen, most recently on the major exhibition Human Hand (Dowse Art Museum, 2020), an installation of video and still imagery focusing on three sites in Arizona: Arcosanti, Biosphere 2 and the Titan Missile Museum. Tim is a founding member of the editorial board of the journal Counterfutures: Left Thought and Practice Aotearoa.
} 
whether one vocation of climate model images is to offer a form of experienced contact with planetary-scale processes of the climate system. "Climate science," says Sheila Jasanoff, "cuts against the grain of ordinary human experience" (Jasanoff 2010, 237). It forms an abstract, distanced form of knowledge, drawing on positivist epistemology and seemingly removed from any embodied ways of knowing climate. Photography theory can help to address the gap between the science of climate change and its experience-to prompt, in Heather Houser's words, "new ways of thinking" about climate, answering Donna Haraway's hope for "another relationship to nature besides reification, possession, appropriation, and nostalgia” (Haraway 2008, 157; Houser 2020, 2).

This project sits alongside recent work by Houser and others, who ask about "the ways data becomes experiential," often through close attention to the aesthetic qualities of climate imagery: their "sophistication, color, perspective, materialization, and allusions to popular genres" (Houser 2020, 32). Birgit Schneider, for example, appeals to the ways color choices in climate visualizations connect them with longer traditions of image-making about the place of humans in the world (Schneider 2016). Houser, for her part, shows how the aesthetics of information itself can lead to emotional responses, and how they can as easily inspire a sense of being overwhelmed as one of positivist mastery.

Such scholars are, then, already concerned with adding another sense to the informational "big story" of climate modeling. This article, however, suggests a different approach to the non- or extra-informational aspects of images. Although I will discuss representational choices and strategies specific to a particular pair of climate model visualizations, the import of photography theory is to alert us to aspects of images that are independent of those choices-of color, say, or aerial perspective. One of the richest features of the photographic image is how it contains aspects that are in excess of the photographer's control, aspects whose author is arguably, as we will see, the world itself. It is my contention that climate model images contain a similar excess.

\section{Climate Visualizations and the Dual Nature of Photography}

This article responds in part to a set of arguments that embed a critique of the apparent objectivity of global climate models within a broader set of problems. T. J. Demos, for example, thinks of global climate model visualizations as "embedded in a specific political and economic framework, comprising a visual system delivered and constituted by the post-Cold War and largely Westernbased military-state-corporate apparatus," and links this notion to Laura Kurgan's description of satellite imagery as "technoscientific, militarized, 'objective”' images (Demos 2017, 16-17; Kurgan 2013, 30). Kurgan, writing largely about the use of satellite imagery to justify military action against Iraq, argues that they were "not objective images, but were presented as such" 
(Kurgan 2013, 25). At one level, of course, this conclusion is hard to avoid given that the claim that they showed weapons of mass destruction turned out to be false. However, the larger point is that the images' objectivity was a matter of rhetoric, and independent of the truth or falsity of the claim-a matter of a way of looking and a way of talking about the images.

By linking global climate model imagery with the imagery of military surveillance, Demos is not only appealing to the context and infrastructure that allows the images to be produced-implicated in a complex of aerospace industries and the military. $\mathrm{He}$ is also giving us reason to question their aesthetic claim to objectivity, and to associate it with the characteristics of distance and power. This takes part in a wider tradition critiquing "Earth from space" surveillance and global mapping imagery, including that of Google Earth, as a product of Cold War military logics (Bonneuil and Fressoz 2016, 59-62; Kurgan 2013). Indeed, it is continuous with arguments about images more generally, that they cannot be taken to provide "a transparent window on the world" (Mitchell 1986, 8), and with Haraway's critique of scientific objectivity in terms of "a perverse capacity-honed to perfection in the history of science tied to militarism, capitalism, colonialism, and male supremacy-to distance the knowing subject from everybody and everything in the interests of unfettered power" (Haraway 1988, 581). I take no issue with these critiques as they stand-"Earth from space" perspectives that global climate models exemplify can be taken to perform the God trick of establishing an apparently disembodied, objective, and distanced perspective. In terms favored by Gayatri Chakravorty Spivak and others, such critical arguments evoke the figure of the globe, an "abstract ball covered in latitudes and longitudes, cut by virtual lines," that contrasts explicitly with that of the planetary-a perspective that opens to the alterity of what it figures (Spivak 2003, 72; Chakrabarty 2019).

Arguments in photography theory suggest that alongside the critical view of how images frame our gaze, there is another way of thinking about images. This is the view according to which photographs have a double nature: despite their capacity to dominate and surveil, they can act as the mechanism by which objects have a sort of agency to disclose themselves. This double nature is expressed in the tendency toward "oppositional thinking" in photography theory, noted by George Baker: "whether we look at the photograph as torn between ontology and social usage, or between art and technology, or between what Barthes called denotation and connotation, or what he also later called punctum and studium, between 'discourse and document' (to use an invention of Benjamin Buchloh), between 'Labor and Capital' (to use one of Alan Sekula's), between index and icon, sequence and series, archive and art photograph" (Baker 2005, 124-125). While these distinctions do not overlap perfectly, there are nonetheless commonalities in the tendency to oppose the pictorial or informational aspect of a photographic image, its tendency to tell a story or frame a scene, with something that simply registers what is in 
front of the lens, which through this brute presence remains uninterpreted or uninterpretable, not able to be incorporated into whatever story the image otherwise tells.

The camera detects what the photographer cannot have intended: textures, expressions, gestures, and other effects that are not a matter of compositional design. As such, it is an indication of the presence of the photographer at the scene:

[T] he detail which interests me [...] does not necessarily attest to the photographer's art; it says only that the photographer was there, or else, still more simply, that he could not not photograph the partial object at the same time as the total object. (Barthes 2000, 47)

Details leak into the story, into what the photographer intended, as something extra. Such unintentional, surprising detail informs what Walter Benjamin referred to as the "optical unconscious": the revealing of a world of detail in slow-motion or close-up photography. The unveiling of these details means more than just expanded knowledge about the world-it offers a new way of seeing, in which "a different nature opens itself to the camera than opens to the naked eye," offering "an immense and unexpected field of action” (Benjamin 1999, 229-30).

Michael Taussig, writing about Benjamin, associates the optical unconscious with the possibility that, via photography, the eye can become "an organ of tactility" - that one can "get hold of something by means of its likeness," achieving "a palpable, sensuous connection between the body of the perceiver and the perceived" (Taussig 1993, 20-21). As Geoffrey Batchen puts it, "the camera does more than just see the world; it is also touched by it. [...] It is as if those objects have reached out and impressed themselves on the surface of a photograph, leaving their own visual imprint" (Batchen 2001, 61).

I do not want to overemphasize the appeal to tactility, at least if the suggestion is that a viewer will necessarily receive it as a physical sensation of touch. Batchen, for example, argues that tactility is as much a factor of the physical form of photographs, and how people hold them and frame them, as it is of the nature of photography itself (Batchen 2001, 60ff). Conversely, Taussig draws a connection between photography and the commodity form, in which there is no perception of tactile, causal contact-in which it is "obliterated into the shimmering copy of the thing perceived," despite the causal mechanics of the labor process that both forms a relationship between people and brings commodities into being (Taussig 1993, 220). In what follows, it will be as well to talk instead of contact, something that is not necessarily perceived and that might need work to draw out of an image. 
The strongest recent case that photographic representations need not only command and surveil comes from photography theorists Ariella Azoulay and Kaja Silverman. For Azoulay, "no photographer, even the most gifted, can claim ownership of what appears in the photograph" (Azoulay 2008, 11) -and she extends this point to argue that even explicit surveillance photographs offer their subjects opportunities for self-presentation and agency. Silverman, whose work I will draw on here, argues that preindustrial photography especially allows for the "self-disclosure of the world" - "the "coming forward' or 'presencing' of the world through self-presentation," through which the world is the author of its own images (Silverman 2015, 47). This self-presentation can be observed in the chemical reaction that occurs on the film photograph's emulsion surface: the development of the image, visible in the darkroom as a suspenseful, unfolding process by which (in early photographer Fox Talbot's phrase) the "pencil of nature" writes, and which is stopped only by the closure of the lens or the application of chemicals to fix the image at a point determined by the photographer.

If there is a broad distinction in photography theory between images' informational aspects and their contact with the world, might a similar distinction be drawn for climate model images? If so, it would mean critiques by Demos and others of "Earth from space" images, including climate model images, apply most clearly only to their informational or pictorial aspects. Those critiques see the images, that is, only for the information they provide and the story they tell. It is a story determined by the perspective and interests that drive the production and deployment of the image-in this case the distanced, militarized apparatus of viewing that the images derive from. The critique of "Earth from space" images is a critique also of the idea that what can be thought using the visualization applies purely and simply to the world visualized - of the idea that the story, the science, and the understanding define and determine their subject without remainder.

However, by paying attention to the other side of the dualism running through photography theory-to the ways in which images refuse transparency, embody contact, present the world in excess of understanding-global climate model visualizations might be redeemed from this critique. What opportunities are there to see climate model images in this light—as the world's self-presentation or self-disclosure, as exceeding and disrupting their tendency otherwise to impose an understanding on the globe?

\section{Contact and Evidence}

The appeal to extra-informational aspects of climate model imagery might seem to shipwreck on a common argument that the contact of the world is only a feature of film photography. These arguments assume a radical break between indexical, emulsion-based photographs and later, supposedly nonindexical digital media, including images deriving from computer climate models. As Mary Ann Doane puts it: 
[T] he indexical image, through its physical connection, touches the real, bears its impression, and hence assures us that it is still there; while the digital image has the potential to abstract and isolate itself, severing any connection with an autonomous reality. (Doane 2007, 140-142)

Lev Manovich wrote in 1995 that digital cinema, by producing a manipulable dataset rather than a physical trace, can "no longer be clearly distinguished from animation. It is no longer an indexical media technology but, rather, a sub-genre of painting" (Manovich 1998, 406). Indeed, Paul Willemen argues that the loss of indexicality results in the potential for full and authoritarian control of the image, thus seemingly sealing, for digital images, the association with domination of their subject - though now falsity and propaganda are the implicit problem, rather than information and surveillance (Willemen 2004, 179-181). The index, then, is a link to the actuality of the world, and a kind of guarantee of its existence. Digital manipulation of images is the extreme case of the determination of their meaning, the reduction of the world's excess to a controlled story.

Scientific modeling, especially where it does not integrate empirical measurements, would seem to be a perfect example of such a nonindexical medium. It would be an example of a postmodern science in Lyotard's sense-a science that gains its legitimacy through performance of its own rules, rather than through reference to the world (Lyotard 1984). Models seem to set in motion only their own internal logics, indeed their own separate worlds, and so might be better described as fictions rather than something from which we might derive an image of the world as such.

It is important to respond to arguments that digital media bear no causal contact with the world, not only for the purposes of my own argument, but also to respond to the implication that they are thereby unfit to provide evidence about the world. The argument that climate modeling has only ever been a fiction is a go-to of the most reactionary climate denialism (Edwards 2010, xviii). I hope it is clear that this is not something I believe. Indeed, the suggestion of a hard distinction between emulsion-based and digital photography is, as Philip Rosen argues, hard to sustain: digital images often derive from causal relations with the world in much the same ways as film photographs, through the focusing of light on a sensitive surface; digital images may be manipulable, but so are film images, and the difference is less one of principle than degree of ease; and digital images can bear similar authority as evidentiary records of events in the world (Rosen 2001, 314ff).

In any case, however, I hope to distance my own argument about contact from arguments about the evidentiary value of climate models-about which I have no doubt. My enquiry is an aesthetic one about how to relate to those images, rather than an epistemological one about their veracity. Contact, in my argument, does not play the role of guarantor of the truth of a model. Paying 
attention to contact means thinking in terms other than evidence through which to view climate model imagery. Silverman, drawing on Benjamin, argues that photography can offer a "disclosive rather than evidentiary form of truth" (Silverman 2015, 7) - a self-disclosure of the world rather than a way of understanding it.

Contact, in fact, need not operate only through the physical trace left on an emulsion surface. Tom Gunning, writing about the moving image, argues that its realism can be as much a kinesthetic effect as an effect of indexicality-an effect of how "we feel [motion] in our guts and throughout our bodies" (Gunning 2007, 39). It is tempting to suggest that the cinema spectator's body receives the kinesthetic impression of the moving figure-dancing with it, taking on its movements-much as an emulsion surface receives the photographic impression of the world. Indeed, for Silverman the world's selfdisclosure through the image (or analogy, in Silverman's terms) can operate through any number of channels, including through the mind and the body of the painter or through digital image-making: "A negative analogizes its referent, the positive prints that are generated from it, and all of its digital offspring, as it moves through time, in search of other "kin"' (Silverman 2015, 11).

The question to ask in relation to climate model imagery is whether there are ways other than the causal mechanics of the film camera by which the image's "big story" might be exceeded on the image surface. Indeed, my initial reason for writing this article came from the visual impression that climate model images, like many visualizations deriving from large datasets, are interesting not only for the narratives they support but also for their fine grained detail, which vastly exceed the narratives.

\section{The World's Self-Disclosure through Climate Visualizations}

I focus here on three aspects of a related pair of climate model visualizations: how the world's self-disclosure works through and against the aesthetic choices made by the images' authors; the visible excess of the image over our comprehension of it; and how contact with the world is visible in the image itself. The images are derived from data from September 2014 to August 2015: simulated data from NASA's Goddard Earth Observing System (GEOS) climate model, and satellite data from the Orbiting Carbon Observatory 2 (OCO-2) satellite. In late 2016 NASA's Scientific Visualization Studio created a series of animated visualizations from this data, showing carbon dioxide levels for that year in three dimensions.

One image, published under the title "Seasonal Changes in Carbon Dioxide," won a "Data Stories" prize from Science magazine for its "departure from the typical flat representation of the data to explain the flow of carbon dioxide at different altitudes" (NASA Scientific Visualization Studio 2016b; "2017 Data Stories Winners" 2017). The image shows carbon dioxide levels above around $400 \mathrm{ppm}$ in a range of warm colors, and those below around 394 $\mathrm{ppm}$ in cool colors, with those in the intermediate range transparent so that 


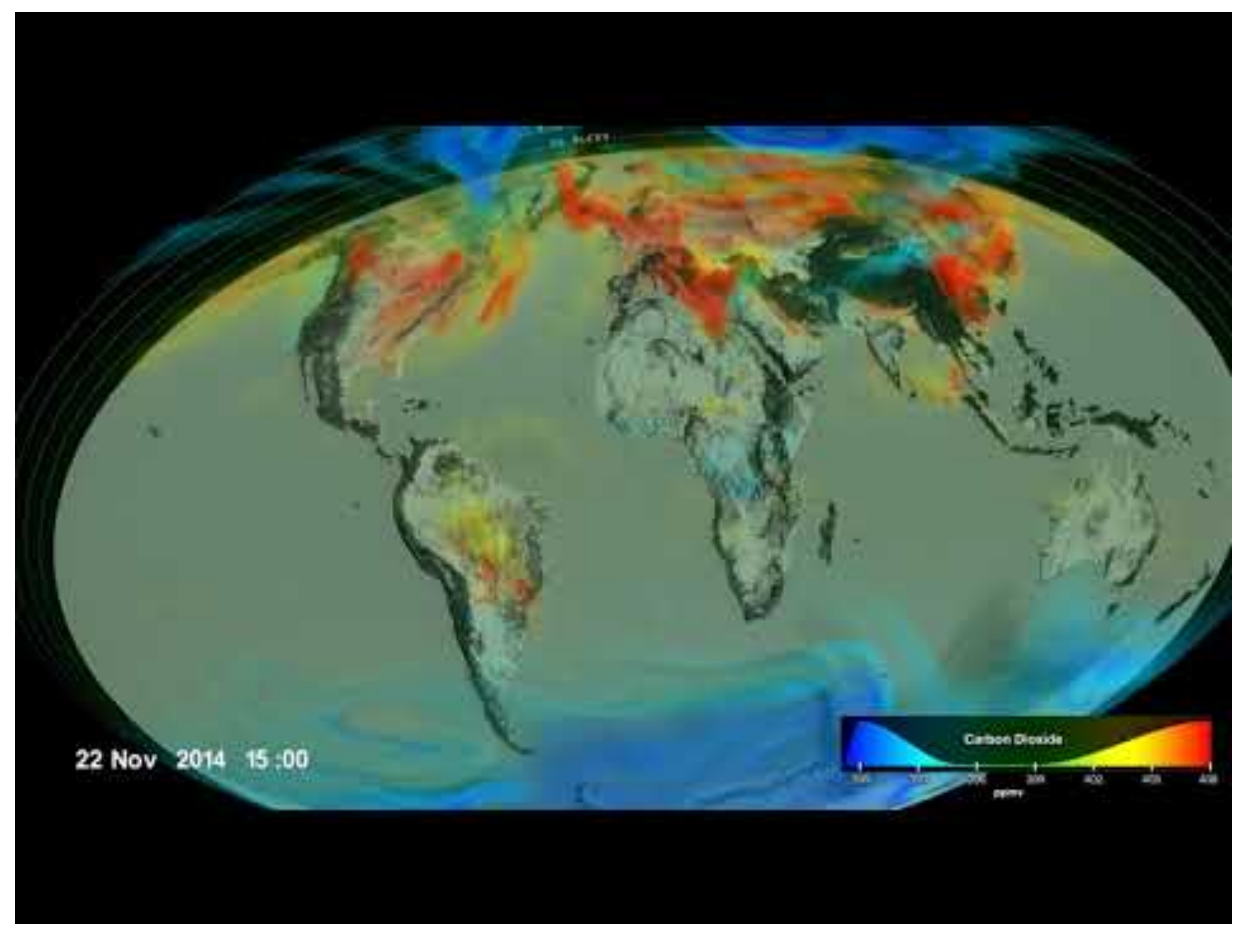

Figure 1: Clip from climate model visualization Carbon Dioxide from GMAO Using Assimilated OCO-2 Data (2016) showing the rotation of the visualization in three dimensions.

Source: Clip made by author from original by NASA Scientific Visualization Studio. Available at https://svs.gsfc.nasa.gov/4514.

Earth's landmasses can be seen below. It begins as a standard flat Mollweidestyle projection showing all of Earth's surface. In this case, however, after the initial frames the flat projection begins to rotate as an elliptical disk, with vastly magnified vertical elevations so that physical gradients appear near vertical. The whole disk is set within a virtual cylinder ringed around with lines representing elevation contours, and within this cylinder the evolving modeled carbon dioxide levels are visible in three dimensions as the cylinder moves within the frame (figure 1).

This image might easily be read alongside Houser's and Schneider's interpretations of climate model images. Following Houser, the numbered vertical axis, alongside the color key and date counter in the lower corners of the image, can give the image an aura of technical sophistication, of detail and data that lend climate model images either scientific authority or a disturbing sense, if here not overly dense, of information excess (Houser 2020, 40-42) Similarly the image presents, at least initially, an aerial view, the abstracted and impossible perspective on the whole planet at once common to many animated climate model images, with similar effects of both mastery and limitation (Houser 2020, 44-45).

The result of the subsequent "rotation" of the map, and its extension into three dimensions, however, shifts the perspective significantly. Earth is transformed into a craggy landscape on a flat plane under swirling red and blue clouds, 
the whole thing contained as if in a snow globe. The spectacular nature of the image-its visual legibility as a contained slice of land and sky-belies the strangeness of the object we are presented with: it is Earth flattened to two dimensions and then remade into a very different three-dimensional view, with an atmosphere of colored clouds that have no basis as bounded objects in Earth's own atmosphere. The numerical figures on the vertical axis are mirrored when we see them from "outside," as if they are written on the transparent wall of the object we are viewing.

The visualization, then, creates a fictional point of view that is not simply aerial, of an object that is not simply Earth or part of it. As such, it differs from many other three-dimensional renditions of climate model data, which give the fictional impression of a flyby, retaining a naturalistic view but from a closer and moving perspective. "Seasonal Changes in Carbon Dioxide," by contrast, is something like a hybrid of world and graph, in which the data is laid out into an artificial, bounded, and labeled presentation space even while viewed from a circling "camera." It hovers abstractly against a black background that cannot be "outer space" if the rotating cylinder is not Earth.

To be sure, "Seasonal Changes in Carbon Dioxide" also resembles something of an abstracted landscape perspective, its landmasses barren and steep and threatened by red clouds. As such, it supports what is perhaps a familiar "big story," a dystopian one of a ruined, scarcely populated terrain. The color choices can be read in this context via Schneider's articulation of climate model imagery with traditions of art images that locate the human in the cosmos. The choice of red, perhaps suggesting a falsely direct association of high carbon dioxide levels with high temperatures, can paint an end-times picture of a burning world in shocking contrast to the familiar, stable "blue marble" imagery characteristic of "Earth from space" views (Schneider 2016). More strangely, the clear or "invisible" representation of the intermediate range gives the impression that in "normal" conditions, between low and high carbon dioxide levels, the gas ceases to exist. Areas of high (and low) carbon dioxide concentration appear, against the clear intermediate range, as objects in themselves, swirling threateningly (or peaceably) over the landscape.

All of these aspects of the image-the deployment of numerical axes and keys, the use of perspective and color-derive from aesthetic choices, and have rhetorical impacts. However, there is another way to read the images that sidesteps the particular nature of those choices. The making of world into a transformed and framed object for viewing foregrounds, more so than any familiar cartographic projection, the aesthetic and constructed nature of the view. The numerical figures are clearly motivated by aesthetic impact, being impossible to "use" for measuring heights, and presented "inward" toward the landscape rather than toward the viewer. Arguably, the defamiliarization of its object might already go some way toward avoiding illusions of transparency. This might mean a shift of attention toward other aspects of the image. It 
can also be taken simply to emphasize the constructed nature of climate visualizations, bringing forward other aspects such as choice of color and transparency as decisions of the artists.

The refusal of a familiar projection or view of the world can also hint at the refusal of a hierarchy of views and projections as such-a sense that no kind of representation is closer or more transparent, in terms of its contact with the world, than any other. Emphasizing the arbitrary nature of aesthetic choices between one projection or color rather than another can also reveal the irrelevance of those choices: the animated cylinder is as much a mark of the world as a cartographic projection; any color choice could carry the sense of contact that is conveyed through them. Compare, in early photography, the lack of a distinction between positives and negatives. Silverman argues that this distinction - and the corollary that positives offered more naturalistic representations of the world-was a historical invention, made use of in industrial processes concerned with reproduction of images rather than the preserving of the world's trace (Silverman 2015, 90-101). Prior to this invention, the daguerreotype image, for example, could seem positive or negative depending on the angle-but more to the point, negative and positive images alike could be viewed as traces of the world. Irrespective of the final tone of the image, the emulsion surface receives the impression of the world and reveals it without need for the representative or associative use of color.

The view created in the "Seasonal Changes in Carbon Dioxide" visualization is, on this argument, at no further remove from some more natural perspective. It is not analogous to a print of a print or a projection of a projection, more or less true than the more accurate or original representation. Irrespective of the process, the stages, the transformations and constructions between world and image, we can take it as the result of a sensitivity to the world's processes. If a model is not the world, then a visualization is not a view. As we will see, however, it might just be one of the world's ways - alongside photography-of revealing itself, of "demonstrating that it exists, and that it will forever exceed us” (Silverman 2015, 10-11).

\section{Data Excess in Climate Images}

The excess of information in the climate model image is not specific to the visualizations I am discussing, but is a feature of any image deriving from large datasets. The visual effect is often that of liquidity or turbulence. When Jeff Wall writes about the "liquid intelligence" of the photographic process, he associates it with the liquidity of early forms of emulsion-linking the mixing of chemicals and the dipping of glass plates with "ancient production processes [such as] washing, bleaching, dissolving, and so on" (Wall 2010, 109)-but also notes the affinity with the photographic capturing of liquid forms in front of the camera. Wall is concerned about the "displacement of water in photography" by the advent of digital media, playing out a "kind of hubris of the orthodox technological intelligence" (Wall 2010, 110). Wall's 


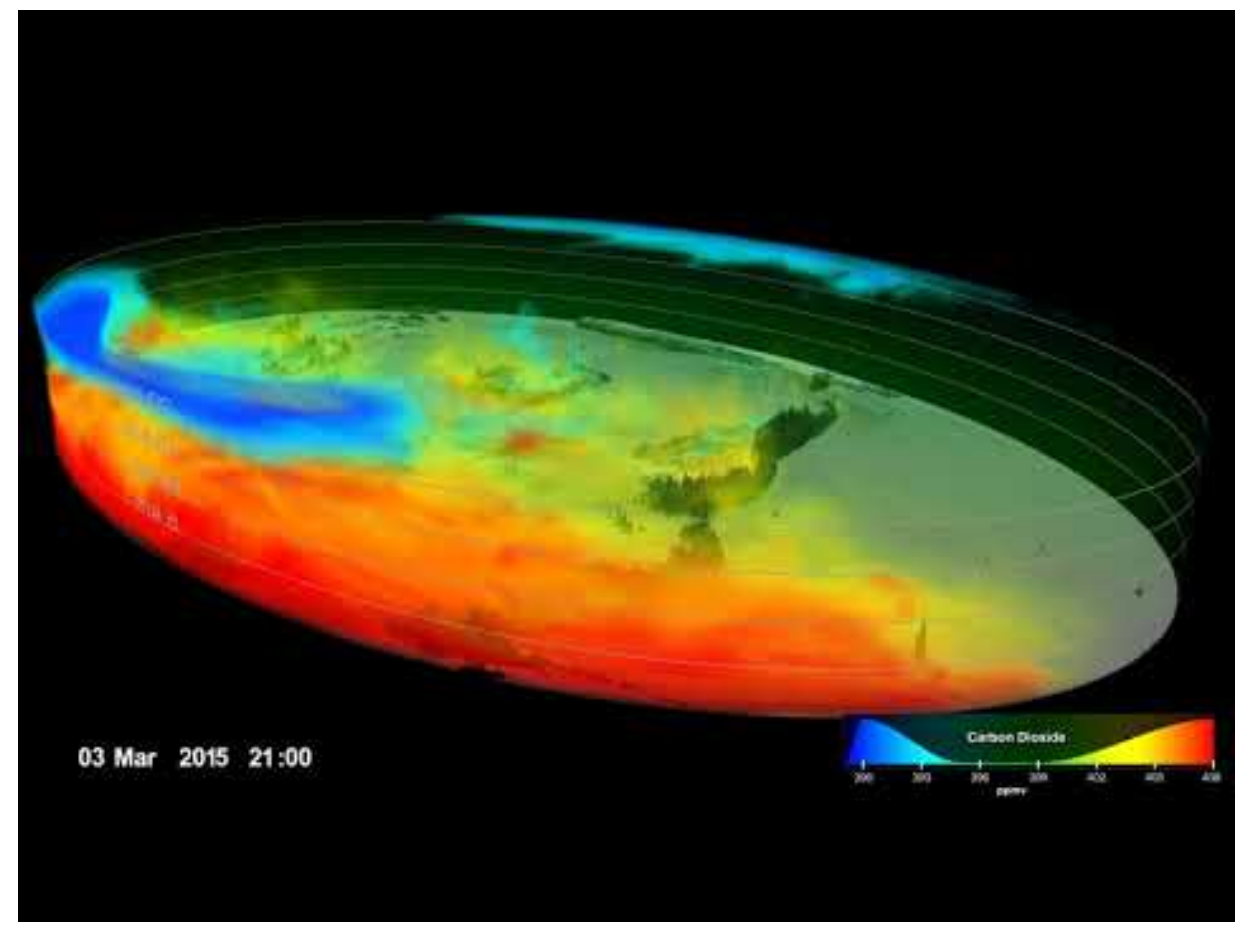

Figure 2: Clip from climate visualization Carbon Dioxide from GMAO Using Assimilated OCO-2 Data (2016) showing turbulence, especially in the top half of the image.

Source: Clip made by author from original by NASA Scientific Visualization Studio. Available at https://svs.gsfc.nasa.gov/4514.

argument echoes, or perhaps repeats outright, something of the critique of the technological gaze rehearsed above. However, even "dry," digital media can retain some sensitivity to the liquidity inherent in earlier photographic processes:

The symbolic meaning of natural forms, made visible in things like turbulence patterns or compound curvatures, is, to me, one of the primary means by which the dry intelligence of optics and mechanics achieves a historical self-reflection, a memory of the path it has traversed to its present and future separation from the fragile phenomena it reproduces so generously. (Wall 2010, 110)

The mention of turbulence patterns is strongly suggestive of climate model imagery and other animated visualizations of large datasets. The effect of turbulence visible in such visualizations is a mark, in part, of very high volumes of data, reflected in the fine detail of data points on the image (figure 2). As such, it suggests the inability of the eye to take in such fine-grained excess of information, or of the mind to comprehend it all at once.

The effect of such detail is the same whether the data derives from empirical measurement or from modeling. As such, the incomprehensible excess might equally be that of the world or of the model, and the eye cannot necessarily distinguish the two. In the case of the climate model image under discussion here, the turbulent swirl of apparent clouds (which do not clearly relate to any 
specific object or process in the world) is the product of the simulated model data rather than the measured input. As I discuss further in the next section, the density of data points from the climate model simulation is far greater than that from the satellite data. Awe at the complexity of their movements, then, is perhaps, when unpacked, closer to awe at sheer computational power-at the possibility of the computer image that emerged during the last half of the twentieth century and that found a popular audience in the dissemination of Mandelbrot, Julia set, and other fractal images in publications like James Gleick's Chaos (Gleick 1987). They promised a derivation of natural forms purely from mathematical principles - and a glimpse, therefore, into the secrets of nature and natural beauty, its simultaneous complexity and regularity.

The effect of information density in computer images reflects, to be sure, a technological-and mathematical-hubris, a belief in the computability or programmability of all phenomena: that every form, natural or otherwise, might be derived from a finitely expressible algorithm (Chun 2011; Finn 2017). The effect of this complexity on viewers may relate to the effect of technical sophistication that Houser, as we have seen, attributes largely to the deployment of multiple modes of information visualization such as graphs, scales, and keys (Houser 2020, 40-42). At the same time, it allows that the visual expressions of computation might continually surprise. While it is possible to program the machine to produce such images, and arguably to comprehend the algorithm that it follows, it remains impossible to humanly predict the final, spectacular shape of the final image or the unbounded complexity of its detail.

The turbulence visible in the climate model images we have been discussing has something of this nature. The climate model is turbulent and complex even in the absence of data deriving from satellite measurement. The visualization of model data shows, as Paul Edwards emphasizes, a world "based on physical theory" (Edwards 2010, xv) - but it is nonetheless a world with the capacity to surprise those who built it. Indeed, this capacity to surprise is part of the point of building models: results can be derived from their operations that are not calculable directly from the theories on which they are built (Corballis 2019; Wise 2011).

Although there is, in the visualization of model data alone, seemingly no equivalent of the photographic emulsion surface's physical trace, this turbulence, the incalculability and excess of detail, comes across as a mark of the world's capacity to exceed our understanding of it. The theories condensed in models are not a matter of simple invention, but (again following Edwards) contain in themselves a history of observation and experiment. Even then, the world as understood in physical theory-even if the theory obscures and simplifies away detail and excess from the observations that ground it-gives rise to detail and excess that resemble that of the world. In this, there is something of the "historical self-reflection" or "memory" that Wall discusses. 
The technical apparatus, even when it is deriving a world from first principles, offers us an image through which to meditate on the world's complexity, even if it is an image whose own detail derives from computation. If, on the one hand, it seems to reduce the whole world to a computable entity, on the other, it gives us a hint, in its unfolding, of how the world might live out its own processes: the fine swirl and movement of the planet as a whole.

\section{The Imprint of the World}

It is useful to read the "Seasonal Changes in Carbon Dioxide" image alongside another visualization, "Assimilation of OCO-2 Carbon Dioxide into the GEOS Simulation," made using the same datasets (NASA Scientific Visualization Studio 2016a). This is something of an instructional video used to demonstrate how empirical data-carbon dioxide levels, derived only from measurements taken by the OCO-2 satellite for 2015-is integrated into the GEOS climate model for that year. Without the integration of empirical satellite data, the model simulation produces carbon dioxide level data based only on the calculation of physical laws, without reference to actual measurements taken throughout the year. Integrating the empirical data with the model serves to ensure that the simulation is not only a construct of theory, while also giving a fuller image than the satellite data allows on its own.

The image maintains a Mollweide projection throughout, but alternates between the two datasets before showing how they are combined. It initially shows the model simulation without empirical input (other than that used to determine initial conditions), then satellite data without model simulation, then a combination of the two. The image is exploded out - that is, into its two aspects, simulation data and empirical data - with the result that when they are recombined, they are separately legible in the overall image.

In the portions of the video showing only satellite data, the recorded levels are visible as a moving line that traces the orbital path of the satellite and registers what it measures. Shown against a flat gray projection of Earth's surface, the data shows up as a thin line, a gappy trace in colors representing the recorded data (figure 3 ). The animation is initially slow, allowing a viewer to follow the movement of the satellite, but speeds up progressively until it becomes a blur covering - albeit in a patchy way_-much of the projection's area as a kind of "sweep" of new data.

Data derived purely from the simulation is then made visible, so it can be seen how the empirical data acts as an overlay and corrective to it. The satellite data points feed into and correct the model data, and through this correction the satellite's movement, its sweep over Earth's surface, comes across as a regular path and pulse, increasing as the speed of the overall simulation is increased (figure 4). This palpable rhythm is, in retrospect, now also detectable in "Seasonal Changes in Carbon Dioxide," as well as in other images that combine model and empirical data. Without the benefit of the demonstration, this pulse 


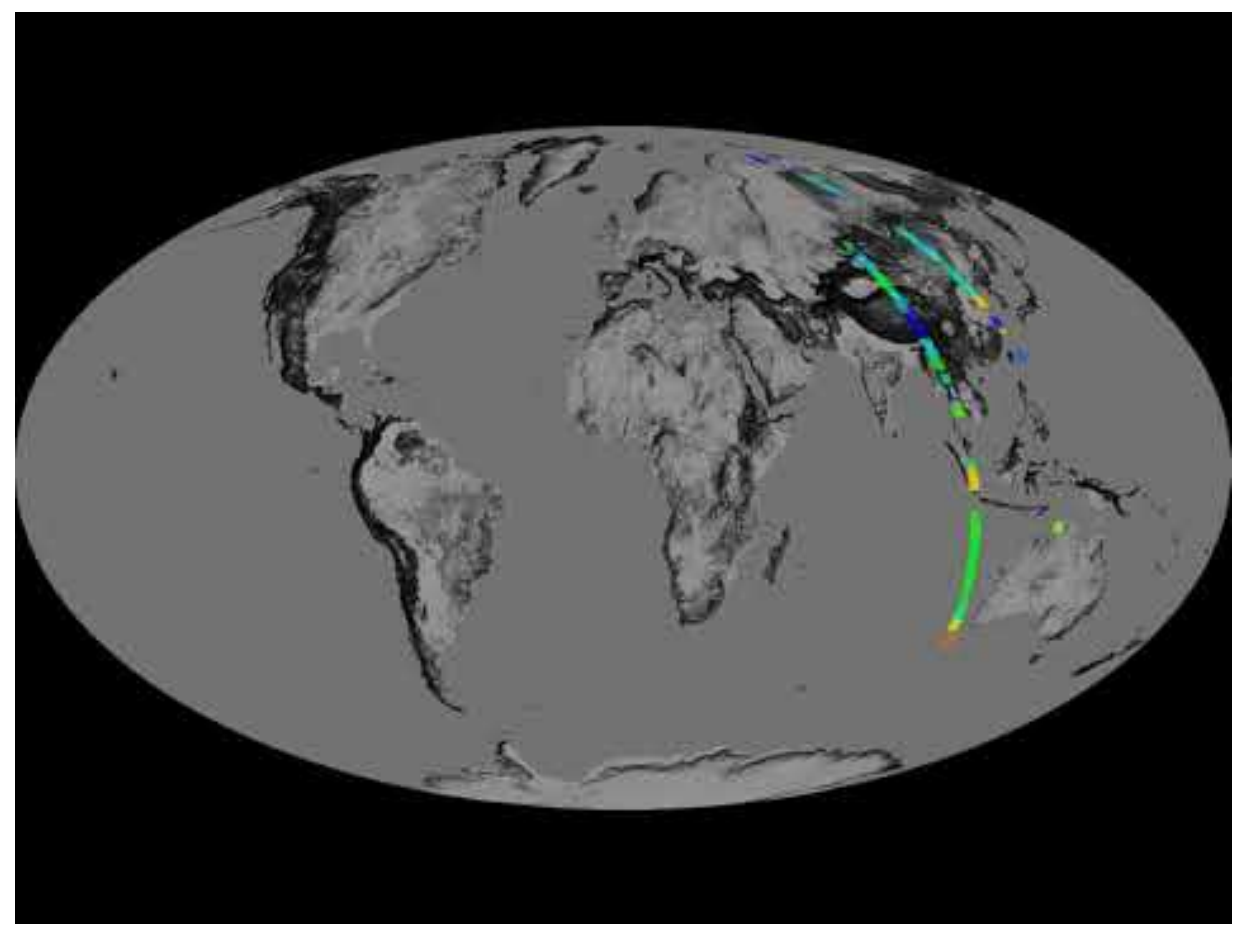

Figure 3: Clip from climate model visualization Assimilation of OCO-2 Carbon Dioxide into the GEOS Simulation (2016) showing data points from the OCO-2 satellite.

Source: Clip made by author from original by NASA Scientific Visualization Studio. Available at https://svs.gsfc.nasa.gov/4519.

is easily interpretable as a "natural" phenomenon rather than an outcome of the way the image was produced: a daily variation in carbon dioxide levels, perhaps, seen as a kind of rhythmic exhalation.

In this sense, the pulse operates as something analogous to a lens flare in film photography —an effect that might be misinterpreted in the final image as the representation of some ghostly emanation, but otherwise shows us a glimpse inside the black box that gave us the image. It is both the shudder of the apparatus and the mark of the world, emerging as it does from the impact of satellite measurement on the model's imagination of the globe. The visible pulse does not offer any information as such about the world, and indeed its rhythm is determined only by the movement of the measuring apparatus, but it marks the impact of the world and the readiness of the model image to receive it.

The satellite data tethers the operation of the model to a set of local, measured states. On their own, however, the empirical measurements are unable to show us a picture of the planet as a whole. For that picture to emerge, the gaps need to be filled in by the model, which condenses a range of results in meteorology, thermodynamics, fluid dynamics, and other physical theory into what might, at a stretch, be considered a kind of thick description-a description that not only pays attention to surface appearances but also theorizes about their meanings and their place in an overall system. It allows us to say, for any local 


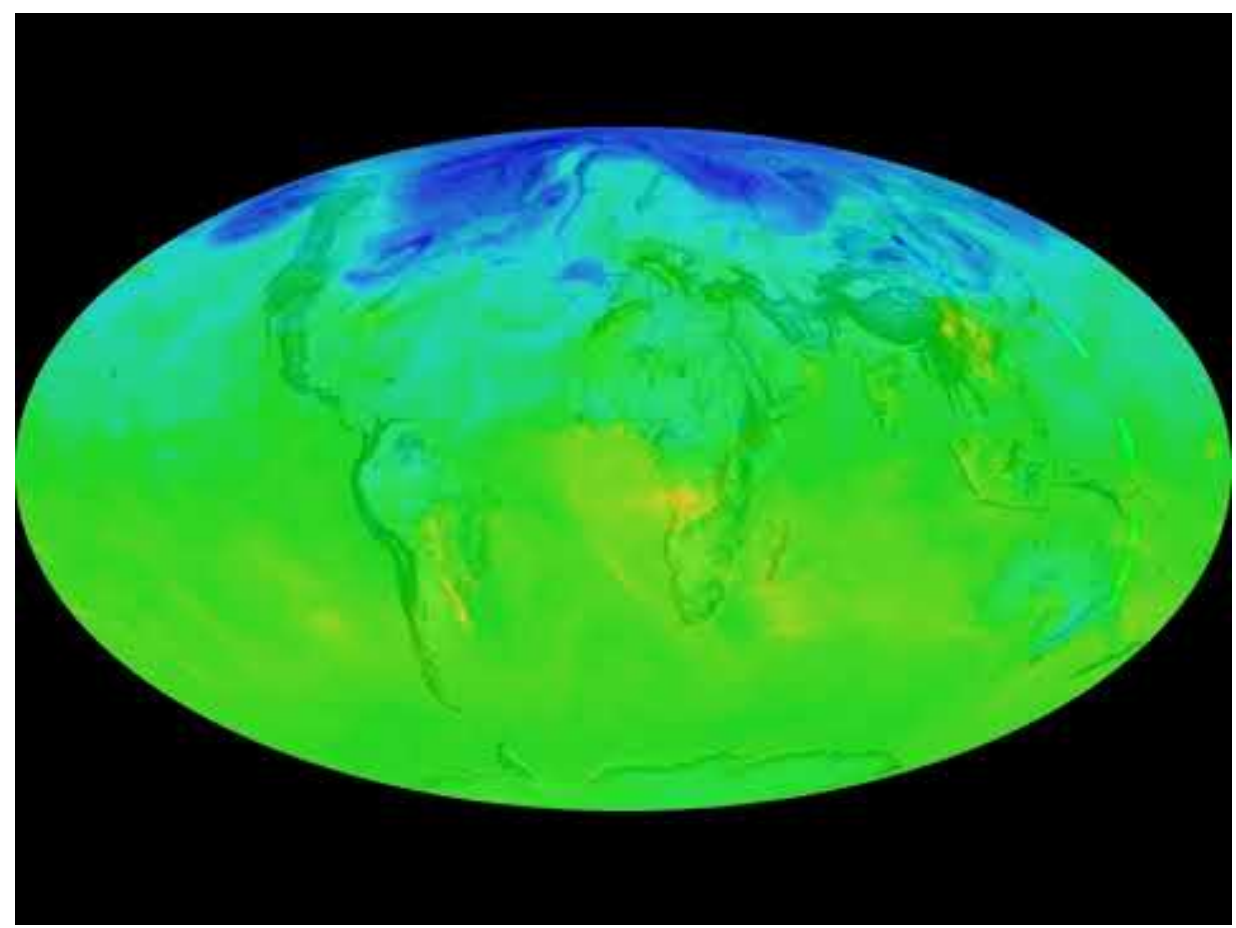

Figure 4: Clip from climate model visualization Assimilation of OCO-2 Carbon Dioxide into the GEOS Simulation (2016). The trace of the satellite data is visible not just where the satellite data is explicitly indicated, but also in faint vertical striping across the width of the image.

Source: Clip made by author from original by NASA Scientific Visualization Studio. Available at https://svs.gsfc.nasa.gov/4519.

URL: https://www.youtube.com/embed/5yNDO9dphKE

measurement, that it gains its importance by fitting into a systemic context, into relationships of causes and spatial movements. What emerges is not just a detailed picture, one that paints the measured points as well as what is between them, but a picture that condenses a large amount of theory and knowledge onto its moving surface.

The rhythm visible in the image is suggestive of two parts of the machine, and the interaction between them: the computer, as it were, and the satellite. It indicates their interplay, the interplay between the theoretical thickness of computer simulation into which a version of physical law is coded, and the sheer presence of a world that the simulation hopes to resemble, but which, we might suggest, exceeds all code. This might evoke the older distinction between lens and emulsion surface in the camera - the "theoretical," framing lens (which comes, in the development of industrial photography, to dominate) and the chemistry of the emulsion, the site of sensitivity that is, for Silverman, progressively tamed and solidified over the course of photography's history. There is no neat correspondence here, of course, but we might read the satellite's registering of the world and disruption of the model image as broadly analogous to a photographic emulsion's own sensitivities, its exceeding of the optical promise of understanding and surveillance. 


\section{Conclusion}

Houser and others have already pointed out that climate model images are "assemblage[s]" whose pictorial coherence is misleading (Houser 2020, 202). I have drawn attention here to a particular kind of tension, or even clash, within the images, deriving from the ways empirical data is incorporated within model simulations. It requires work to see the effect of different kinds of imagery in them - the trace of the world amid the complex visual modeling of fluid dynamics. However, it is precisely such a reading that can give a sense of the world, of its presence and complexity, even its unrepresentable nature. To return to Spivak's terminology of planet and globe, "[ $\mathrm{t}]$ he globe is on our computers. [...] It allows us to think that we can aim to control it" (Spivak 2003,72 ). The dry intelligence of our computers can nonetheless also allow a sense of the planet's uncontrolled alterity.

Silverman's remarkable evocation of the photographic image moving through time in search of its kin-via the mechanics of the camera, the reproduction of the image, even its digitization and human perception-is suggestive. The operation of the satellite, and the integration of its data with the model simulation, allow the planet to find kin in the resulting image. That the match is imperfect, that we are dealing with kin not copy, is something that can be seen and ultimately, perhaps, felt. It contains a reminder and a register of the movement of the satellite and the touch of the planet's climate. On its own the satellite data is thin, a tracing over the map's surface. However, placed imperfectly amid the model data, it is given context of movement and liquidity, the physicality performed through modeling the processes that it emerges from.

The model provides, of course, an imperfect and still impoverished picture of the world. It is depopulated and depoliticized, made over into physics only-even if the effects of the human hand are detectable in rising carbon dioxide and temperature data. There is physical truth, even no doubt climate truth, left unexpressed. Like all knowledge, the knowledge they express should be understood as a partial outcome of the technologies and infrastructures that produce them. All of this is to say that when we look at climate model imagery, we do not look at the whole world.

We do however look at the planet-at the planetary scale and processes that occur at that scale. This is a rare thing. Talking about visualizations of ecological field site data, Danielle Svehla Christianson warns against a forgetting of the sense of interconnection implicit in being in the field itself: "As this type of visual representation becomes more available, ecologists will need to grapple with the allure of the ready-made virtual environs that calls the scientist to the desk rather than to the forest" (Svehla Christianson 2020). When we turn to the global processes revealed by climate model visualizations, however, there is no equivalent way to connect to them-there is no field science, no direct experience, of the planetary scale. This is how we should 
understand Edwards's claim that "Everything we know about the world's climate-past, present, and future-we know through models" (Edwards 2010, xiv). There are many ways to connect in a situated, embodied way to climates, but the planet as known by climate models, a planet defined by the flow and detail of planetary circulation systems and patterns, reveals itself in no way other than through the infrastructures that record and model global data. The global climate model visualization, then, can lead us to follow and study the major circulation patterns, oscillations and waves; but it can also give us a sense of contact with the planetary, with the world's physics as a system.

Christophe Bonneuil and Jean-Baptiste Fressoz suggest that "the scientists of the Earth system [are] the bearers of a relationship to the world that has precisely produced the danger that they warn us of and offer to save us from" (Bonneuil and Fressoz 2016, 95). If we agree with Edwards, it is nonetheless important to pay close attention to the work of those scientists. That means it is all the more important to practice a way of looking at that science-at its imagery - that sidesteps the God trick implicit in it, the hint of knowledge and domination, and that aims at another relationship: a relationship sensitive to the excess of the planet over our understanding of it, and ultimately therefore opposed to the sense that it could fall under our control. 


\section{REFERENCES}

“2017 Data Stories Winners.” 2017. Science. https://www.science.org/content/page/2017-datastories-winners.

Azoulay, Ariella. 2008. The Civil Contract of Photography. New York: Zone Books.

Baker, George. 2005. “Photography's Expanded Field.” October 114 (October): 120-40. https://doi.org/10.1162/016228705774889574.

Barthes, Roland. 2000. Camera Lucida: Reflections on Photography. London: Vintage.

Batchen, Geoffrey. 2001. Each Wild Idea: Writing, Photography, History. Cambridge, MA: MIT Press. https://doi.org/10.7551/mitpress/2541.001.0001.

Benjamin, Walter. 1999. Illuminations. London: Random House.

Bonneuil, Christophe, and Jean-Baptiste Fressoz. 2016. The Shock of the Anthropocene. London: Verso.

Chakrabarty, Dipesh. 2019. “The Planet: An Emergent Humanist Category.” Critical Inquiry 46 (1): 1-31. https://doi.org/10.1086/705298.

Chun, Wendy Hui Kyong. 2011. Programmed Visions: Software and Memory. Cambridge, MA: MIT Press. https://direct.mit.edu/books/book/3341/Programmed-VisionsSoftware-and-Memory.

Corballis, Tim. 2019. "Populating the Climate: Narrative in and with Climate Models." Environmental Philosophy 16 (2): 275-89. https://doi.org/10.5840/envirophil201981284.

Demos, T. J. 2017. Against the Anthropocene: Visual Culture and Environment Today. Berlin: Sternberg Press.

Doane, Mary Ann. 2007. "The Indexical and the Concept of Medium Specificity." differences 18 (1): 128-52. https://doi.org/10.1215/10407391-2006-025.

Edwards, Paul N. 2010. A Vast Machine: Computer Models, Climate Data, and the Politics of Global Warming. Cambridge, MA: MIT Press.

Finn, Ed. 2017. What Algorithms Want: Imagination in the Age of Computing. Cambridge, MA: MIT Press. https://direct.mit.edu/books/book/4491/What-Algorithms-WantImagination-in-theAge-of.

Gleick, James. 1987. Chaos: Making a New Science. New York: Viking.

Gunning, Tom. 2007. "Moving Away from the Index: Cinema and the Impression of Reality." differences 18 (1): 29-52. https://doi.org/10.1215/10407391-2006-022.

Haraway, Donna Jeanne. 1988. "Situated Knowledges: The Science Question in Feminism and the Privilege of Partial Perspective.” Feminist Studies 14 (3): 575-99. https://doi.org/10.2307/ $\underline{3178066 .}$.

- - . 2008. "Otherworldly Conversations: Terran Topics, Local Terms." In Material Feminisms, edited by Stacy Alaimo and Susan Hekman, 157-87. Bloomington: Indiana University Press.

Houser, Heather. 2020. Infowhelm: Environmental Art and Literature in an Age of Data. New York: Columbia University Press. https://doi.org/10.7312/hous18732.

Jasanoff, Sheila. 2010. "A New Climate for Society.” Theory, Culture E' Society 27 (2-3): 233-53. https://doi.org/10.1177/0263276409361497.

Kurgan, Laura. 2013. Close Up at a Distance: Mapping, Technology, and Politics. New York: Zone Books. https://doi.org/10.2307/j.ctt14bs159.

Lyotard, Jean-François. 1984. The Postmodern Condition: A Report on Knowledge. Minneapolis: University of Minnesota Press.

Manovich, Lev. 1998. "What Is Digital Cinema?” In The Visual Culture Reader, 2nd ed., 405-16. Abingdon, UK: Routledge. 
Mitchell, W. J. T. 1986. Iconology: Image, Text, Ideology. Chicago: University of Chicago Press. https://doi.org/10.7208/chicago/9780226148052.001.0001.

NASA Scientific Visualization Studio. 2016a. "Assimilation of OCO-2 Carbon Dioxide into the GEOS Simulation.” https://svs.gsfc.nasa.gov/4519.

- - . 2016b. "Carbon Dioxide from GMAO Using Assimilated OCO-2 Data." https://svs.gsfc.nasa.gov/4514.

Rosen, Philip. 2001. Change Mummified: Cinema, Historicity, Theory. Minneapolis: University of Minnesota Press.

Schneider, Birgit. 2016. "Burning Worlds of Cartography: A Critical Approach to Climate Cosmograms of the Anthropocene." Geo: Geography and Environment 3 (2). https://doi.org/ $10.1002 /$ geo2.27.

Silverman, Kaja. 2015. The Miracle of Analogy: Or, the History of Photography, Part 1. Stanford, CA: Stanford University Press. https://doi.org/10.1515/9780804794008.

Spivak, Gayatri Chakravorty. 2003. Death of a Discipline. New York: Columbia University Press.

Svehla Christianson, Danielle. 2020. “01100110 0110111101110010011001010111001101110100 [Forest].” Media+Environment 2 (1). https://doi.org/10.1525/001c.13389.

Taussig, Michael. 1993. Mimesis and Alterity: A Particular History of the Senses. London: Routledge. Wall, Jeff. 2010. “Photography and Liquid Intelligence." In Jeff Wall: The Complete Edition, 109-10. New York: Phaidon.

Willemen, Paul. 2004. "Reflections on Eisenstein and Digital Imagery: Of Mice and Men." In The Montage Principle: Eisenstein in New Cultural and Critical Contexts, 171-89. Amsterdam: Rodopi. https://doi.org/10.1163/9789004334472_009.

Wise, M. Norton. 2011. "Science as (Historical) Narrative.” Erkenntnis 75 (3): 349-76. https://doi.org/10.1007/s10670-011-9339-2. 